Original Research Paper

\title{
Pelatihan Pendampingan Proposal Penelitian Tesis Magister untuk Mahasiswa Magister Pendidikan IPA dalam Masa Pandemi Covid-19
}

\author{
Aris Doyan ${ }^{1}$, Susilawati $^{2}$, Ahmad Harjono \\ ${ }^{1}$ Magister Pendidikan IPA, Pasca Sarjana, Universitas Mataram, Mataram, Lombok, NusaTenggara Barat, Indonesia. \\ ${ }^{2}$ Program Studi Pendidikan Fisika, PMIPA, FKIP, Universitas Mataram, Mataram, Lombok, Nusa Tenggara Barat, Indonesia
}

DOI: https://doi.org/10.29303/jpmpi.v3i2.510

Sitasi : Doyan, A., Susilawati., \& Harjono, A. (2020). Pelatihan Pendampingan Proposal Penelitian Tesis Magister untuk Mahasiswa Magister Pendidikan IPA dalam Masa Pandemi Covid-19. Jurnal Pengabdian Magister Pendidikan IPA, 3(2)

\section{Article history}

Received: 7 July 2020

Revised: 28 August 2020

Accepted: 2 November 2020

*Corresponding Author:

Aris Doyan,

Program Studi Magister IPA,

Universitas Mataram,

Mataram, Lombok, Nusa

Tenggara Barat, Indonesia.

Email:aris_doyan@unram.ac.id

\section{Pendahuluan}

Program pascasarjana yang ditempuh oleh para pelajar yang ingin melanjutkan studinya setelah lulus pada jenjang S1 membutuhkan biaya yang tidak sedikit. Selain untuk biaya hidup dan keperluan buku, biaya perkuliahan magister juga meliputi biaya penelitian tugas akhir (tesis). Mahasiswa yang memiliki kendala dalam keuangan akan merasa berat dalam proses menjalani kuliahnya tersebut. Untuk dapat memperoleh bantuan dana dalam penelitiannya, mahasiswa perlu

\begin{abstract}
Telah dilaksanakan pelatihan pendampingan kepada mahasiswa Pascasarjana Universitas Mataram khususnya pada mahasiswa program studi Pendidikan IPA secara online. Pelaksanaan pengabdian masyarakat ini walaupun dimasa Pandemi covid-19 secara online tidak mengurangi minat mahasiswa dalam bekerja dan terus mencari informasi untuk dapat membantu menyelesaikan studinya. Tujuan pengabdian ini merupakan wujud sosialisasi program Ristekdikti dalam bidang penelitian tesis mahasiswa, sebagai peluang untuk mahasiswa mendapatkan dana hibah dalam tugas akhirnya. Salah satu peluang tersebut adalah dengan mengikuti seleksi nasional dalam Penelitian Tesis Magister (PTM) bersama dosen pembimbing. Biaya penelitian tesis yang tidak sedikit akan menjadi salah satu hambatan mahasiswa magister dalam proses penyelesaian studinya. Dengan adanya PTM ini mahasiswa yang bersangkutan akan dapat dibantu dari dana PTM tersebut apabila lulus dalam seleksi PTM yang diikuti. Agar dapat lulus seleksi dalam PTM, mahasiswa magister perlu mengetahui tentang PTM. Selain itu, mereka juga perlu untuk mempelajari cara-cara untuk dapat lulus dalam PTM. Pelatihan tentang penulisan PTM yang telah dilakukan mendapatkan respon positif sehingga mahasiswa berhasil menyelesaikan proposalnya.
\end{abstract}

Keywords: Penelitian Tesis Mahasiswa, Pandemi, Covid-19

mengikuti kompetisi-kompetisi yang menawarkan bantuan dana penelitian (Farooq, \& Khan, 2011). Akan tetapi, mahasiswa kurang mendapatkan informasi tentang kompetisikompetesi yang menawarkan bantuan dana penelitian tersebut, salah satunya yaitu Penelitian Tesis Magister (PTM). Mahasiswa yang kurang mendapatkan informasi tentang PTM tersebut akhirnya tidak dapat mengikuti kompetensi tersebut. Terdapat sebagian mahasiswa yang telah mengetahui informasi tentang PTM, namun mereka tidak memiliki kemampuan untuk membuat proposal PTM yang layak untuk diterima. Hal ini bisa terjadi karena mereka tidak pernah membuat 
dan mengikuti kompetensi yang seperti itu, sehingga mereka tidak memiliki pengalaman dalam membuat proposal PTM. Akibatnya, hanya sedikit mahasiswa yang ikut dan lulus dalam kompetensi PTM tersebut (Hetami, 2008).

Berdasarkan analisis situasi di atas, maka permasalahan yang dirumuskan adalah sebagai berikut. Bagaimana meningkatkan kemampuan mahasiswa Magister Pendidikan IPA UNRAM dalam menulis proposal bantuan dana hibah melalui kompetensi Penelitian Tesis Magister (PTM)?

\section{Metode}

Menanggapi permasalahan yang mengakibatkan kurangnya kemampuan mahasiswa magister dalam mengikuti kompetensi penelitian dana hibah dalam Penelitian Tesis Magister (PTM), maka permasalahan ini dapat diselesaikan dengan cara memberikan pelatihan kepada mahasiswa Magister Pendidikan IPA UNRAM. Beberapa tahapan yang akan dilalui dalam penyelesaian masalah ini yaitu tahap persiapan, tahap pelaksanaan, dan tahap evaluasi. Secara sederhana tahapan ini direpresentasikan dalam Gambar 1 berikut (Jagero, et al., 2012).

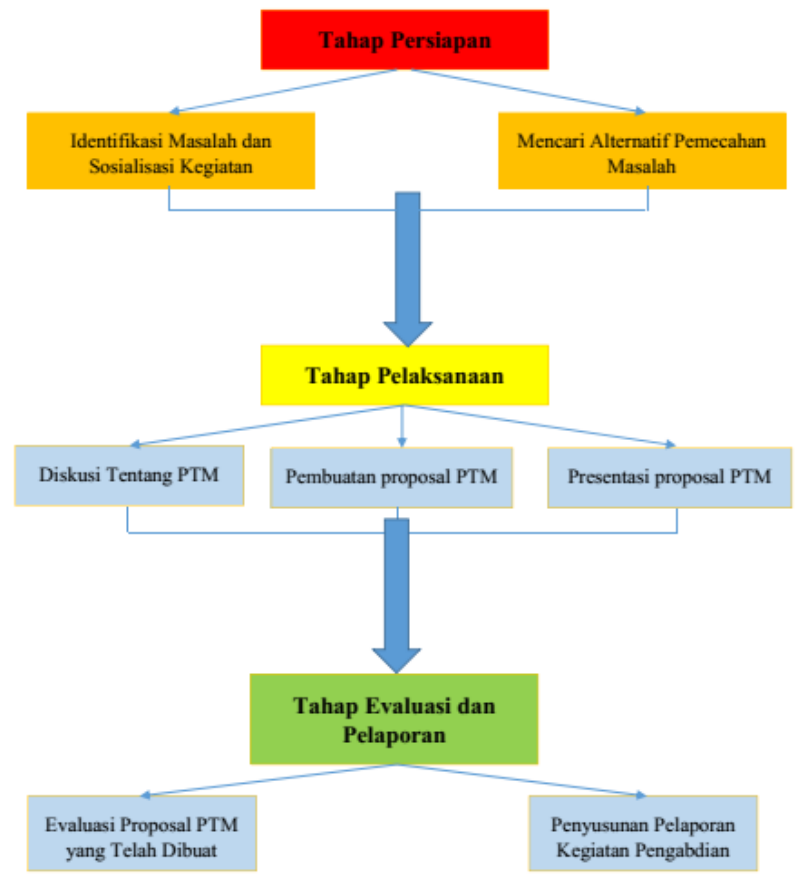

Gambar 1. Kerangka Pelaksanaan Kegiatan Pengabdian

\section{- Tahap Persiapan}

Pada tahap persiapan dilakukan observasi terhadap mahasiswa Magister Pendidikan IPA UNRAM, guna untuk mengidentifikasi permasalahan yang dihadapi dalam penulisan proposal Penelitian Tesis Magister (PTM). Hasil observasi ditemukan bahwa mahasiswa Magister Pendidikan IPA UNRAM kurang mendapatkan informasi mengenai PTM, sehingga mereka tidak mengetahui cara penulisan proposal yang akan dikompetisikan dalam PTM tersebut. Salah satu upaya untuk menyelesaikan masalah tersebut adalah dengan dilakukan pelatihan kepada mahasiswa Magister Pendidikan IPA UNRAM khusus semester dua agar dapat menulis proposal PTM dengan baik dan benar, sehingga dapat lulus seleksi untuk diberikan dana hibah penelitian.

\section{- Tahap Pelaksanaan}

Pada tahap pelaksanaan ini merupakan tindak lanjut untuk menyelesaikan permasalahan yang dialami mahasiswa Magister Pendidikan IPA UNRAM tentang PTM, yaitu dengan dilaksanakan pelatihan langsung mengenai cara penulisan proposal PTM yang baik dan benar, sehingga dapat lulus seleksi untuk diberikan dana hibah penelitian. Pada tahapan ini, mahasiswa yang telah membuat proposal PTM akan diminta untuk mempresentasikan proposal PTM yang telah dibuat selama proses pelatihan berlangsung. Proses pelatihan pembuatan proposal PTM dilakukan dengan berpedoman pada panduan penulisan PTM yang terbaru.

\section{- Tahap Evaluasi dan Pelaporan}

Evaluasi hasil pelatihan dilakukan secara langsung dengan menilai hasil proposal PTM yang telah dibuat oleh mahasiswa Magister Pendidikan IPA UNRAM. Pelaporan kegiatan pengabdian dilakukan dengan menyusun laporan pelatihan penyusunan proposal PTM pada mahasiswa Magister Pendidikan IPA UNRAM.

\section{Hasil dan Pembahasan}

Pelatihan yang diberikan diikuti 17 orang peserta dari mahasiswa magister IPA, 5 orang peserta dari mahasiswa magister administrasi pendidikan dan 3 orang mahasiswa dari magister lahan kering, sehingga berjumlah 25 orang peserta. 
Semua mahasiswa di pandu melalui zoom meeting, dengan membuat WhatApps group. Dalam komunikasi digroup, mahasiswa di pandu dengan menjelaskan aturan aturan yang berlaku di PTM pada buku panduan Ristekdikti edisi XII (Sefriady \& Iskandar 2018) 2 berikut.

Kegiatan pelaksanaan terlihat pada Gambar

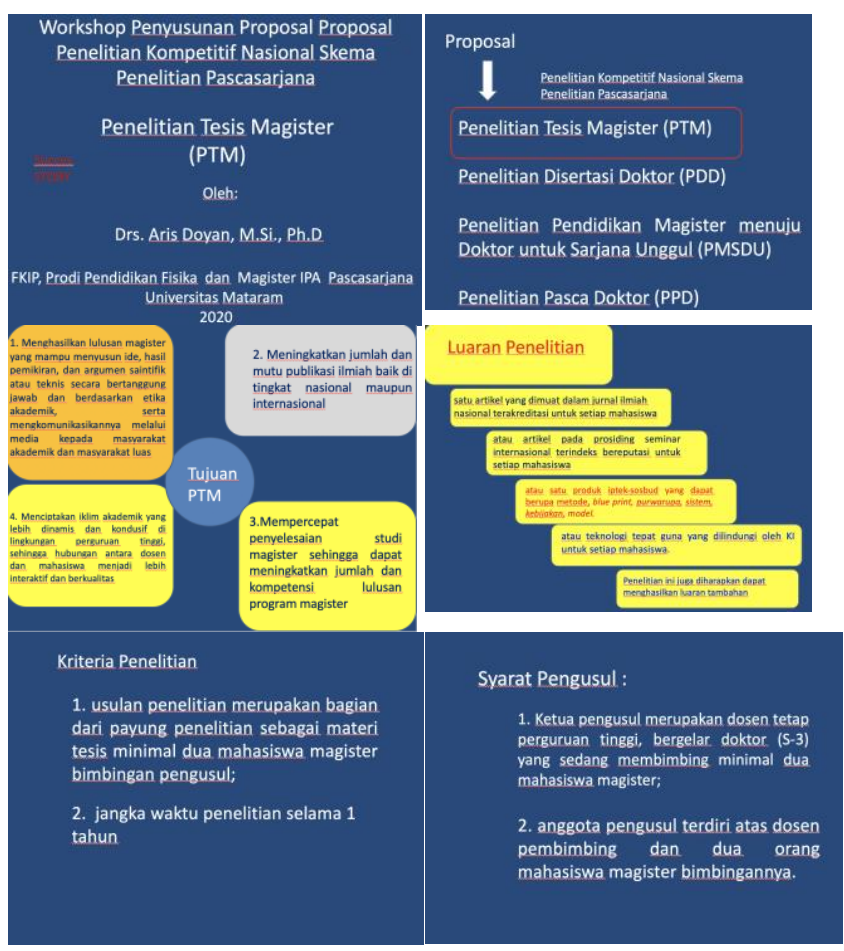

Gambar 2. Pelaksanaan Kegiatan Pengabdian

Setelah proses pelaksanaan peserta di bimbing untuk menghasilkan proposal PTM dari pemilihan judul, latar belakang, rumusan masalah, tujuan penelitian, urgensi penelitian. Kemudian dilanjutkan dengan tinjauan Pustaka, metode penelitian dan penulisan referensi. Hasil pembimbingan penulisan PTM terlihat pada gambar 3 berikut.

Dari gambar 3 terlihat salah satu hasil sosialisasi PTM mahasiswa sudah mahir membuat proposal dan siap untuk di submit ke sistem simlibtamas ristekdikti (Sultana, et al., 2012; Yuliati, 2009)
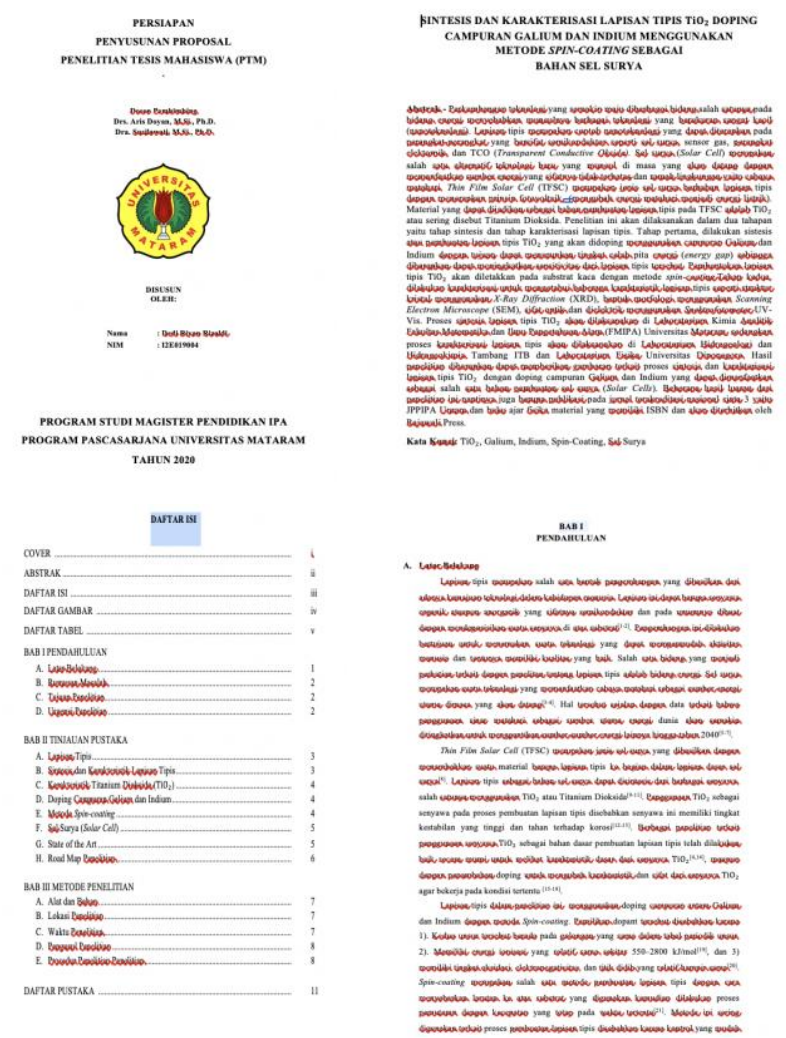

Gambar 3. Contoh Bentuk Proposal PTM

\section{Kesimpulan}

Pelatihan pendampingan pembuatan proposal penelitian tesis mahasiswa telah berhasil dilaksanakan dari tahap perencanaan, pelaksanaan, dan evaluasi dan pelaporan kinerja peserta. Keberhasilan ditandai dengan sudah siapnya proposal yang di kerjakan dan siap untuk di submit di sistem simlibtamas Ristek Dikti untuk tahun 2021 dengan kondisi new normal.

\section{Saran}

Diharapkan setelah new normal pelatihan dapat dilaksanakan dalam proses tatap muka atau offline sehingga menghasilkan PTM yang lebih berkualitas.

\section{Ucapan Terima Kasih}

Penulis mengucapkan terima kasih kepada program studi magister IPA, program studi magister administrasi pendidikan, dan program studi lahan kering, dan Universitas Mataram yang 
telah mendanai pengabdian ini dengan BLU Unram no. $2145 / \mathrm{UN} 18 / \mathrm{LPPM} / 2020$.

\section{Daftar Pustaka}

Farooq, M., \& Khan, M. A. 2011. Impact of Training and Feed Back on Employee Performance. Far East Research Centre, 5 (1): $23-33$.

Hetami, A. A. 2008. Pengaruh Motivasi, Kemampuan dan Disiplin terhadap Kinerja Karyawan pada Sebuah Persero Asuransi. Jurnal Ekonomi dan Bisnis, 6 (2): 66 - 81.

Jagero, N., Komba, H. V., \& Mlingi, M. N. 2012. Relationship Between on the Job Training and Employee's Performance in Courier Companies in Daressalam, Tanzania. International Journal of Humanities and Social Science, 2 (22): 114 - 120.

Panduan Penelitian dan Pengabdian Pada Masyarakat edisi XII, Ristek Dikti 2018.

Sefriady, D. F., \& Iskandar, D. A. 2018. Pengaruh Pelatihan dan Disiplin Kerja Terhadap Kinerja Pegawai di Biro Organisasi dan Kepegawaian Sekretariat Jenderal Kementerian Perdagangan. Jurnal Elektronik REKAMAN (Riset Ekonomi Bidang Manajemen dan Akuntansi), 2 (1): $57-68$.

Sultana, A., Irum, S., Ahmed, K., \&Mehmood, N. 2012. Impact of Training on Employee Performance: A Study of Telecommunication Sector in Pakistan. Interdisciplinary Journal Of Contemporary Research In Business, 4 (6): 646 - 661.

Yuliati, S. 2009. Pengaruh Motivasi dan Pelatihan Terhadap Kinerja Karyawan Politeknik Pratama Mulia Surakarta. Politeknosains VIII (2): 20-31. 